\title{
Uma interpretação psicológica dos "limites" do domínio moral: os sentidos da restrição e da superação
}

\section{A psychologyc interpretation of moral field limits: the meaning of restriction and overcoming}

\author{
Yves de La Taille*
}

\begin{abstract}
RESUMO
O presente artigo visa propor uma tradução psicológica à expressão "limites”, muito empregada na educação moral. Para tanto, são analisadas duas dimensões dos limites. A primeira: os limites no sentido da restrição de liberdade, que correspondem aos deveres morais. A segunda: os limites no sentido da superação, que correspondem aos ideais, ao auto-aperfeiçoamento, às virtudes. As duas dimensões são discutidas do ponto de vista moral e do ponto de visa psicológico, procurando mostrar que são indissociáveis. Palavras-chave: Limite, moral, dever, virtudes.
\end{abstract}

\begin{abstract}
The aim of this paper is to propose a psychological interpretation for the expression 'limits', often used in moral education. We analyse two dimensions of limits. The first: limits as restriction of freedom, so, limits as duty. The second: limits as overcoming, so as ideals, as self-improvement,
\end{abstract}

* Professor Doutor do Instituto de Psicologia da Universidade de São Paulo. ytaille@originet.com.br 
as virtues. We discuss both dimensions in moral and psychological terms, and we try to show that they are intimately associated.

Key-words: Limit, moral, duty, virtue.

A palavra "limite" costuma ser muito empregada na linguagem cotidiana. Ela pode ter, em alguns casos, um sentido preciso, notadamente quando se trata de espaço (os limites de uma propriedade). Mas ela também pode servir de imagem para remeter a atividades humanas: por exemplo, dizemos que um atleta superou seus próprios limites, ou que uma pessoa carece de limites. Como se trata de uma imagem, seu significado permanece vago: de que limites estamos falando? O objetivo do presente artigo é justamente o de propor uma tradução técnica à palavra limites no campo da psicologia moral. A motivação para fazê-lo vem de dois fatos. O primeiro: existe, na sociedade atual, notadamente na educação (familiar e escolar), uma queixa moral a respeito da "falta de limites" das crianças e dos adolescentes. Programas de televisão, artigos de revistas, entrevistas, livros etc. são realizados em torno desse tema. Mas qual é exatamente o tema? É preciso equacionar a questão. O segundo: nesse contexto de queixas, a palavra limite vem exclusivamente associada a uma única forma de se empregar a referida imagem: o limite restritivo, o limite como proibição. Mas, como acabamos de ver, limite também pode remeter à superação. Ora, pouco se pensa nesse sentido, notadamente quando se trata de moral. É preciso, então, nos perguntarmos se tal restrição de sentido é legítima, ou se traduz um erro, uma lacuna. Veremos que, de fato, tratase de uma lacuna importante.

O texto que vamos ler será dividido em duas grandes partes: 1) limites no seu sentido restritivo e 2. limites no seu sentido de superação. Cada parte será subdividida em dois subitens: a) definição do termo limite, b) equacionamento psicológico deste.

\section{Limites: sentido da restrição}

\section{a) definição}

Expressões como "os alunos não têm limites", "é preciso impor limites", ou ainda, "há limites que devem ser respeitados", remetem à ordem da obrigação, da proibição, da restrição de liberdade. Em termos morais, reme- 
tem à questão do dever. O dever moral traduz-se por afirmações como tal coisa não pode ser realizada (dever negativo: por exemplo, não se pode matar) ou tal coisa não pode não ser feita (dever positivo: por exemplo, não se pode deixar de ajudar alguém em perigo de vida). Os deveres negativos, ou seja, aqueles que traduzem uma proibição relativa a uma ação, são os mais freqüentes, e implicam clara restrição de liberdade. Os deveres positivos são menos lembrados e também implicam restrição de liberdade: se devemos fazer alguma coisa, é que não temos o direito de agir de outra forma. Em resumo, os limites, no seu sentido restritivo, indicam fronteiras que não devem ser ultrapassadas, ações que não podem ser realizadas ou que não podem deixar de ser realizadas, logo, os limites remetem à restrição de liberdade que, em termos morais, chamamos de dever.

Isto posto, podemos nos perguntar se os deveres morais representam uma necessidade social, ou se são apenas facultativos. Perguntando de outra forma: pode haver forma de comunidade que não implique restrição de liberdade de ação por parte de seus membros? Ora, a resposta é certamente negativa. Não há sociedade que não limite a liberdade de seus membros, que não lhes coloque certas proibições, certas obrigações, logo, certo deveres. Em seu clássico texto Mal-estar na civilização, FreUd (1974) escreveu que os animais são bem mais livres do que os homens porque sobre eles não pesam as coações sem as quais a civilização seria impossível. Daí sua tese: o preço que se paga para usufruir dos benefícios da civilização, ou seja, do viver em uma comunidade organizada, é um certo "mal-estar" psicológico decorrente das repressões que a sociedade exerce, e da nostalgia de uma liberdade perdida. É evidente que as restrições de liberdade, logo, os deveres, podem ser diferentes de uma sociedade para outra (embora alguns cruciais encontram-se em todos os lugares, como a proibição do incesto, do assassinato, da mentira) e também que o número de deveres pode ser superior numa sociedade em relação a outras (as sociedades democráticas dão mais liberdade a seus membros do que aquelas regidas por um estado religioso). ${ }^{1}$ Mas o fato é que, em qualquer forma de organização social, limites são colocados, deveres são exigidos.

Do que acabamos de escrever, decorre que a questão dos limites restritivos está inevitavelmente presente na educação das crianças e dos jovens. E isso desde os primórdios da civilização. Basta olhar para as formas de edu-

1 Deve-se lembrar também que os limites podem ser mais numerosos para certas pessoas do que para outras, embora vivam na mesma comunidade. Ainda é caso em certas sociedades nas quais as mulheres têm menos liberdade de ação do que os homens. 
cação tradicionais para notar que temas como o dever, a disciplina, o respeito pela autoridade, a obediência estavam presentes, aliás, bem presentes. Ora, hoje, há uma clara queixa em relação ao respeito pelos limites por parte das novas gerações, e isso tanto na família quanto na escola. Impõe-se a pergunta: o que aconteceu para que uma dimensão tão antiga e necessária do aculturamento das crianças e jovens cause, hoje, problemas? Impõe-se também um diagnóstico de bom senso: certamente não se trata apenas de problemas técnicos, didáticos, que um bom manual de pedagogia possa resolver. Com efeito, não é concebível que uma certa "amnésia" pedagógica tenha acometido a sociedade, seus adultos, seus educadores. Não queremos dizer com isso que a dimensão pedagógica não deva ser analisada. Mas, parece-nos indispensável, sob pena de reduzirmos um problema social a uma questão de técnica, ter clareza de que questões de ordem social devem ser evocadas para explicar a referida queixa a respeito da falta de limites dos educandos. Sem espaço, aqui, para analisar essas questões, limitamo-nos a arrolar algumas: falta de limites nos próprios adultos, que têm seus filhos e alunos como reflexo de seus próprios valores e comportamentos, crise geral de valores, individualismo entendido como o sentimento de isolamento decorrente do clima social de "cada um por si e ninguém por todos", fragilização das relações sociais, despotencialização da família, o medo de ser autoritário. Dos itens arrolados, será que algum é mais relevante, mais presente? É difícil responder. Eles certamente mesclam-se, interpenetram-se, compondo um quadro confuso. Cada um dos itens mencionados mereceria ser analisado e as relações entre eles, equacionadas. Mas vamos limitar agora nosso campo de reflexão e conhecer o que a Psicologia Moral tem a nos dizer sobre a construção de limites (no sentido deveres) por parte das crianças.

\section{b) aspectos psicológicos}

O leitor terá percebido que acabamos de empregar o verbo "construir" para nos referirmos à legitimação dos limites restritivos. Somos então construtivistas? Sim, mas tal cartão de visita teórico em quase nada ajuda para situar um autor, notadamente na área da moralidade. $\mathrm{O}$ conceito não somente tornou-se moda (com toda a superficialidade que tal fato implica) como recobre perspectivas teóricas bastante variadas, como, por exemplo, a de Piaget, a de Vygotsky e a de Wallon. Nossa tarefa agora será a de chegar à definição do que pode se entender por "construção", no sentido piagetiano, na área da moralidade, e de verificar o que tal abordagem tem a nos dizer sobre os limites no seu sentido restritivo. 
Como a teoria construtivista piagetiana foi elaborada em oposição a outras perspectivas, talvez seja importante, para avaliar sua singularidade, conhecê-las.

Antes de qualquer elaboração teórica por parte da Psicologia, a educação moral tradicional, evidentemente, já existia, e repousava sobre três princípios. O primeiro: a moral é obra de Deus ou da sociedade, e deve ser imposta às novas gerações; o processo se dá, portanto, de fora para dentro. $\mathrm{O}$ segundo: essa imposição somente pode ocorrer na relação adulto/criança. $\mathrm{O}$ terceiro: forma e conteúdo se confundem no sentido em que entendemos por moral, não um sentimento sui gêneris (que pode receber o nome de moralidade), apto a receber diversos valores (até contraditórios entre si), mas sim a legitimação de um determinado sistema de valores e regras, a saber, aquele da sociedade em que cresce a criança.

Herdeira dessa visão pedagógica, a Psicologia vai, pouco a pouco, desconstruindo- $a$, para empregar um conceito atual. Por exemplo, em Freud e Durkheim, os dois primeiros princípios serão referendados, enquanto o terceiro será abandonado. Em compensação, em Piaget, os três princípios serão reformulados.

Comecemos então pela abordagem de Durkheim. Em seu belo e pungente livro sobre a educação moral (1974), o sociólogo francês pergunta-se se é possível alguém aderir à moral sem que esta apareça como obra de Deus. A resposta de Durkheim é positiva pois, para ele, existe, nos homens, uma disposição psicológica para a moral. Vale dizer, para ele, existe o fenômeno psicológico da moralidade, esta entendida como predisposição para legitimar deveres. ${ }^{2}$ Tal moralidade está assentada no sentimento do sagrado, fusão entre o sentimento da obrigatoriedade (o dever), e aquele da desejabilidade (o Bem). Logo, para que um sistema de valores possa ser legitimado por uma pessoa, é necessário que este sistema desperte nela o sentimento do sagrado. Não há dúvidas de que a idéia de Deus (Cristão) reúne as condições necessárias para tal despertar. Deus é todo poderoso, onipotente, e nada podem os homens contra a sua vontade: eis a fonte do sentimento da obrigatoriedade. Deus é também visto como puro amor, como justiça, como começo e fim do universo, logo como coisa desejável: eis a fonte do sentimento da desejabilidade. Mas, para Durkheim, não é apenas a idéia de Deus que pode

2 Entendemos, aqui, moralidade como se entende "religiosidade". 
despertar o sentimento do sagrado: a sociedade também pode fazê-lo porque suas leis necessariamente coagem seus membros (para Durkheim, o todo - a sociedade - determina as qualidades de suas partes - os membros da sociedade) e porque toda a riqueza de que os homens podem usufruir dela provém (eles não podem prescindir dos objetos culturais - linguagem, arte, técnica, ciência etc.). Logo, a sociedade pode ser objeto do sentimento do sagrado, necessário à moralidade. Porém, tal sentimento somente poderá existir se certas disposições pedagógicas forem tomadas em relação às crianças. Entendemos agora porque Durkheim abandona o terceiro princípio da educação moral tradicional, a saber, a não dissociação entre forma e conteúdo da moral. Com efeito, se existe uma moralidade (sentimento do sagrado), esta pode ser despertada por vários sistemas morais (e não apenas um), contanto que provenham de algo visto como poderoso e desejável. Aliás, quando perguntam ao sociólogo que moral ensinar ele responde: a vigente na sociedade em que se dá a educação.

Se Durkheim abandona o terceiro princípio da educação moral tradicional, tal não acontece com os dois primeiros. Como acabamos de ver, a moral é, para ele, sempre elaborada pela sociedade e imposta a seus membros (primeiro princípio), e, logo, a relação hierárquica adulto/criança é mantida pois é o primeiro que pode, como representante da sociedade, fazer com que o sentimento do sagrado se desenvolva no segundo princípio.

Vamos agora rapidamente ver como FREUD (1991) equaciona a questão. Assim como para Durkheim, podemos dizer que o pai da psicanálise admite a existência da moralidade, ou seja, de uma predisposição psicológica especial a aceitar deveres. Para tanto, ele faz a hipótese de que se desenvolve, durante a infância, uma instância psíquica particular que ele chama de superego (e também de Ideal do ego), responsável pelo pensar e agir morais dos homens. Que valores e que regras ocuparão este lugar psíquico? Ora, os valores e as regras colocadas pelos adultos significativos para a criança, com destaque para o pai. Novamente, vemos que o terceiro princípio da educação moral tradicional encontra-se ausente pois forma e conteúdo diferenciam-se. A forma é a moralidade, o superego, e o conteúdo será aquele com o qual a criança terá tido contato graças à sua convivência com os pais. ${ }^{3}$ Quanto aos dois outros princípios, Freud não os con-

3 Notemos que, como o superego não é, para Freud, apenas o lugar dos deveres morais, mas sim dos deveres em geral, poderíamos argumentar que não, ele não defende a tese da existência da "moralidade", mas sim da existência do lugar psíquico responsável pelo sentimento de obrigação. Não vamos discutir essa possibilidade aqui. 
tradiz: a moral é imposta de fora para dentro, imposta pelos adultos (com destaque para os pais, enquanto Durkheim dava destaque aos professores).

Antes de vermos a abordagem piagetiana, devemos verificar que, nas duas teorias até agora apresentadas, os deveres morais são impostos às crianças, logo os educadores devem colocar "limites" e cobrar a obediência a eles.

Piaget (1932) vai, como dissemos, se contrapor aos três princípios. Como Durkheim e Freud, ele aceita a hipótese de uma moralidade, ou seja, de um desenvolvimento psíquico particular (embora integrado a outras dimensões psíquicas, notadamente à inteligência). Todavia, ele não aceita a separação entre forma e conteúdo. Ou melhor, forma e conteúdo começam, para ele, por estar separados para, no fim da gênese, encontrarem-se. Vejamos como isso se dá.

Como sabemos, Piaget fala em "duas morais da criança": a heteronomia e a autonomia, sendo que a segunda é superação da primeira, logo, posterior na gênese. O que é heteronomia? Em linhas gerais, é uma moral da obediência (nome que o próprio Piaget também lhe dá), uma moral, portanto, baseada no respeito pelos mandamentos da autoridade, uma moral do respeito unilateral. Mas, qual o conteúdo dessa moral? Ora, aquele que a autoridade (os pais e professores na maioria dos casos) impõe. Assim, para a explicação da fase de heteronomia, Piaget faz dele as idéias de Durkheim: existe uma moralidade, seu conteúdo é aquele imposto pelos adultos, e tal imposição acontece justamente porque há uma hierarquia dos adultos em relação às crianças. Todavia, enquanto para Durkheim (e também para Freud) a moral humana está explicada assim, para Piaget a história continua: a criança conquista paulatinamente a autonomia. O que é a moral autônoma? É a moral que se baseia sobre a igualdade, o respeito mútuo, o reconhecimento da dignidade do ser humano, a justiça baseada na eqüidade. Logo, e isso é da maior importância, a moral autônoma tem um conteúdo que a define. É por esta razão que escrevemos que, no fim da gênese, forma e conteúdo encontram-se: a moralidade é a forma, e a igualdade, a justiça baseada na eqüidade, as relações humanas de respeito mútuo são o conteúdo. Vale dizer-mos que a moral autônoma não é qualquer moral, pois nela não cabem todos os deveres que, na moral heterônoma, podiam estar presentes em razão das decisões da autoridade. Esta nova interpretação da moralidade humana faz cair os dois primeiros princípios da educação moral tradicional. O primeiro, conforme o qual a moral é imposta de fora para dentro, cai porque, se a gênese da moralidade leva necessariamente a uma moral específica, é que há uma participação ativa da criança na construção de seu universo moral. O segundo princípio, conforme o qual a educação moral depende exclusivamente da influência dos adultos 
sobre as crianças, também cai porque, segundo Piaget, são as relações entre iguais que promovem os ideais igualitários da justiça, são as relações de cooperação (e não de obediência).

Estamos agora em condições de explicitar o que nos parece ser a interpretação construtivista dos limites restritivos (deveres morais). A apresentação das três teorias escolhidas permitem-nos fazer a distinção entre legitimar a moral e legitimar uma determinada moral. Legitimar a moral significa desenvolver a moralidade, ou o que TugEndHAT (1998) chama de "senso moral" (moral sense), ou seja, aceitar intimamente restringir a própria liberdade, limitála. Legitimar uma determinada moral significa escolher que deveres serão aceitos, que limites serão respeitados. Assim, duas pessoas com senso moral não necessariamente respeitarão os mesmo limites. É o que vimos em Piaget. Para ele, a criança heterônoma tem senso moral, e aceita os limites que lhe são impostos pelos adultos, e a pessoa autônoma permanece tendo este senso moral, mas referenda apenas os limites condizentes com a justiça e o respeito mútuo. Logo, a tarefa educacional deve enfrentar tanto o desenvolvimento do senso moral quanto o do conteúdo da moral. Ora, como a heteronomia é anterior à autonomia, decorre da posição piagetiana que o desenvolvimento da moralidade, logo, do senso moral, depende, num primeiro momento, de relações assimétricas, do exercício da autoridade por parte dos educadores. Sem elas, com efeito, não se concebe que a criança entre no que podemos chamar de mundo moral. Uma vez desenvolvido este senso moral durante a fase de heteronomia, o desenvolvimento moral prossegue rumo à autonomia, notadamente graças às relações de cooperação. Mas, vamos repeti-lo, a autonomia é uma superação da heteronomia, não uma alternativa à ela desde os primeiros anos da infância. Ora, o que pode estar acontecendo, hoje, com certas crianças e jovens, é que eles não desenvolveram um senso moral, não aceitam limites de forma alguma, recusam qualquer restrição de liberdade. Este quadro não corresponde nem à heteronomia moral, nem à autonomia: corresponde à anomia. Para que alguém conquiste a autonomia moral, é preciso que aceite pertencer a uma comunidade moral. Tal aceitação se dá antes da autonomia.

Para finalizar esta primeira parte, voltemos rapidamente a duas reflexões de ordem geral que fizemos a respeito das possíveis razões da atual queixa de falta de limites das crianças e dos jovens. Apontamos uma certa crise de valores morais, uma indecisão de vários adultos em relação ao que deve ser proibido e permitido, ao que é certo e ao que é errado. Ora, se tal for o caso, portanto, se as crianças são educadas num certo flou ético, se nada lhes é claramente colocado como dever, é compreensível que elas não desenvol- 
vam, ou o façam de maneira lacunar, sua moralidade, seu senso moral. Apontamos também o medo dos pais e professores de serem autoritários, o medo de formarem jovens meramente obedientes, conformistas, passivos, não críticos, em uma palavra, heterônomos. Tal medo é justificável, e boa parte da pedagogia moderna reza que os alunos devem ter iniciativa, devem ser ativos, construir seus conhecimentos e seus valores. Todavia, tal busca da conquista da autonomia por parte dos jovens acaba por fazer esquecer que ela é superação da heteronomia. $\mathrm{O}$ resultado prático desta pedagogia é que os jovens acabam por não ter contato com a moral, com os deveres, uma vez que os adultos, de medo de se imporem, silenciam sobre seus próprios valores. Reflitamos sobre o que o filósofo Tugendhat nos diz a respeito de Jesus de Nazareth, para ele um grande reformador moral: "Ele relativizou e ampliou a moral que era a de seu povo, coisa que ele não poderia ter feito se tivesse rejeitado por completo esta moral para colocar outra. Como todo reformador, ele precisava extrair de forma estrutural uma nova moral do mundo social [...]" (p. 58). Se quisermos que os jovens façam a moral evoluir, se quisermos que seja críticos, não é escondendo nossa moral que chegaremos a esta desejável meta. Pelo contrário, devemos expor claramente nossos valores e nossas regras para que possam ser avaliadas, aceitas ou criticadas, reformadas. Escreveu Piaget:

O respeito mútuo é uma espécie de forma limite de equilíbrio para a qual tende o respeito unilateral, e pais e professores devem fazer todo o possível para se converterem em colaboradores iguais às crianças. Cremos, no entanto que esta possibilidade depende da própria criança, e que durante os primeiros anos um elemento de autoridade fatalmente se mescla às relações que unem as crianças aos adultos. A verdade parece estar entre os dois e consiste em não negligenciar nem o respeito mútuo nem o respeito unilateral, os dois fontes essenciais da vida moral infantil (1998, p. 28).

\section{Limites: sentido da superação}

a) definição

A palavra "limite" também é empregada em expressões populares que remetem a superação, vitória, esforço. Assim, por exemplo, dizemos de um 
atleta que "superou seus próprios limites". Verificamos que tal emprego da palavra não fala em ausência de limites, mas sim da existência destes, cuja superação é admirável. Expressões que dizem respeito à superação de limites são empregadas essencialmente para falar de proezas físicas (o esportista, o doente), mas também podem ser encontradas em referência a vitória sobre certas dificuldades psicológicas (vencer o medo, timidez etc.). Todavia, raramente estão associadas à moral. Ora, essa ausência traduz, na verdade, uma séria lacuna, pois a superação de limites tem lugar de destaque para a dimensão moral.

Tomemos, por exemplo, a filosofia de KANT (1985). Para ele, a moral reside no dever, portanto na restrição de liberdade. Logo, sua posição parece ater-se ao limite restritivo. Isso pode ser até verdade para os deveres chamados de negativos: não matar, não mentir, não roubar etc., ou seja não fazer o mal. Mas há os deveres positivos que visam, e isto é diferente, fazer o bem, promover o bem estar dos homens. Por essa razão, Kant coloca, como um dos dois deveres fundamentais de cada homem, promover a felicidade de outrem. Ora, é claro que, para agir na intenção de promover o bem, não basta não realizar ações moralmente más, é preciso também pensar sobre as ações boas, criá-las, inventá-las. Dito de outra forma, fazer o bem pressupõe um investimento afetivo e cognitivo, um esforço para se tornar uma boa pessoa. E, como acabamos de dizer, ser uma boa pessoa não equivale a não ser uma má pessoa. Uma pessoa pode até não ser má, no sentido de não realizar ações moralmente condenáveis, e ainda assim ser incapaz de promover o bem. É por essa razão que Kant também afirma que ao lado do dever de promover a felicidade dos homens, existe outro, também fundamental: o do aperfeiçoamento pessoal. Ora, o que é tal auto-aperfeiçoamento senão a procura do desenvolvimento pessoal, do crescimento, do superar limites? O que Kant nos diz é que, para ser moral, para ser digno, é preciso todo um trabalho sobre si mesmo no sentido da busca da excelência. Em uma palavra: é preciso ser virtuoso.

O tema da virtude também encontra-se na obra de ARISTóteles (1963). A moral aristotélica não é baseada no dever, mas sim na busca da felicidade, da realização da vida plena, na busca da sabedoria. E, para ele, tal busca somente é possível no desenvolvimento de várias virtudes, como generosidade, magnanimidade, humildade, justiça. É claro que Kant e Aristóteles têm posições diferentes em relação aos fundamentos e objetivos da moral. Mas o que é importante notar aqui, é que apesar da diferença de posição, esses autores não limitam a moral à obediência passiva a mandamentos negativos, ambos nos remetem à idéia da boa pessoa, da vontade boa, e ambos também pensam 
que, para ser uma boa pessoa, é preciso esforço, crescimento, busca da excelência, superar os próprios limites. Aliás, tal idéia encontra-se também em outros autores, como Spinoza (1954), Pascal (1972), Smith (1999), e, mais perto de nós, Thugendhat (1998), MacIntyre (1981) e ComteSPonville (1995): moral relaciona-se à virtude, ou às virtudes, e virtudes são características admiráveis da personalidade (o caráter), características essas que não derivam de um dom da natureza, mas sim da superação dos próprios limites em direção à excelência moral, em direção a ideais.

Ora, assim como, na primeira parte desse artigo, ponderamos que o respeito pelos limites restritivos sofria de dificuldades oriundas de um certo "clima" moral contemporâneo, é possível também pensar que a busca de superação de si (e não apenas no campo da moral) enfrenta dificuldades advindas de certos valores que são dominantes hoje em dia, como a onipresença da competitividade (ter como referência apenas o outro, e não a si próprio), as virtudes vistas como perniciosas à referida competitividade (o generoso é "deixado para traz", o humilde é "desprezado", o justo é "otário" etc.), o "politicamente correto" que referenda a mediocridade (não se pode criticar), e o individualismo entendido como preguiçosa autocomplacência. Mas, deixemos a análise desse clima moral para outra ocasião, e vejamos o que a Psicologia tem a nos dizer sobre os limites a serem superados.

\section{b) aspectos psicológicos}

Comecemos por lembrar que teorias, como as de Piaget (1932) e KoHlBerg (1981), apontam para o fato de haver um desenvolvimento moral (dois estágios para Piaget, seis para Kohlberg). Logo, nessa perspectiva teórica, a moral não é meramente interiorizada pelas crianças, mas depende de uma atividade suis gêneris de construção que consiste em erguer-se de níveis inferiores para níveis superiores. A autonomia é uma conquista decorrente de esforços empreendidos desde a infância para expandir o domínio moral, tornálo mais complexo e nuançado. Em suma, há um desenvolvimento moral (nunca realmente acabado) que implica superação dos próprios limites.

Vejamos uma outra dimensão psicológica que implica a presença de limites a serem superados. Estamos nos referindo à abordagem de Freud. Vimos na primeira parte de nosso texto que, na sua interpretação do fenômeno da moralidade, ele havia feito a hipótese da existência psíquica responsável pelo sentimento do dever: o superego. Mas, vamos lembrá-lo, esta instância psíquica também foi por ele batizada de Ideal do ego. Como apontado por TUGENDHAT (1998), ao dar dois nomes para a instância psíquica responsável 
pela moral, Freud sublinhou dois aspectos inseparáveis de toda moral: por um lado o dever e por outro, os ideais a respeito do que seja o Bem, a boa pessoa, a virtude ou as virtudes. Para Freud, o superego é o lugar do dever, portanto do limite restritivo, e o Ideal do ego, o lugar, como seu nome indica, dos ideais que inspiram as ações, dos limites a serem superados. Portanto, assim como em Piaget e Kohlberg a moral é vista como crescimento, em Freud ela é vista como aspiração (os ideais dão sentido aos mandamentos do superego).

Poderíamos nos dar por satisfeitos com a lembrança do fato de que, para Piaget, Kohlberg e Freud, moral não é, do ponto de vista psicológico, apenas, e nem essencialmente, restrição de liberdade. Porém, precisamos ir um pouco além e abordar uma nova perspectiva que, de forma explícita, implica o limite a ser superado para a ação moral.

Para introduzi-la, analisemos o seguinte dilema pedagógico. Imaginemos que uma criança esteja batendo noutra e que um adulto intervenha para apartar a briga. Imaginemos também que este adulto pergunte ao agressor por que está agindo desta maneira e que este responda que é porque está sentindo ódio de seu colega. O que responder a ele? É aqui que se coloca o dilema. Podemos responder: "você está sentido ódio, entendi, mas, mesmo assim, não pode bater no seu colega". Ou pode-se responder: "você não pode sentir ódio de seu colega". Vemos a diferença entre as duas respostas. Enquanto a pri-

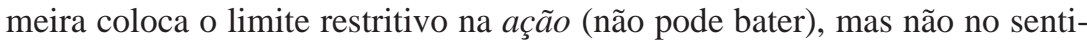
mento (ódio) que motivou tal ação, a segunda coloca o limite restritivo no sentimento (não pode sentir ódio). Ou seja, na primeira resposta, diz-se que a pessoa não tem o direito de traduzir seu sentimento de ódio em ação, e na segunda, diz-se que ela não tem o direito de experimentar esse sentimento. Qual a melhor? Dois planos colocam-se para pensar a resposta. Um plano é o da moral: somos ou não condenáveis pelos nossos sentimentos? Se a resposta for afirmativa, e se considerarmos que sentimento como ódio faz parte dos sentimentos proibidos, a alternativa pedagógica que se impõe é responder ao agressor que ele não pode sentir raiva ou ódio. Em compensação, se nossa opção moral reza que somos apenas culpados pelas nossas ações (sendo a parte afetiva da esfera exclusivamente íntima e não passível de sanção), a alternativa correta seria dizer à criança que não pode bater, seja qual for o sentimento que a motiva. Evidentemente, não cabe à Psicologia resolver esta questão, do ponto de vista moral. Mas ela pode tratá-la no plano que é o seu. E, no plano psicológico, podemos indagar o que segue: é possível, é viável, colocar limites restritivos sobre a afetividade? Perguntando de outra forma: pode alguém proibir-se de experimentar diversos sentimentos, como ódio, 
amor, inveja, compaixão, raiva, simpatia? Ora, pensamos que a resposta que as teorias psicológicas, notadamente a psicanalítica, dão, é negativa. Os sentimentos surgem com bastante independência em relação à consciência, à razão. É claro que é possível uma pessoa sentir-se culpada de sentir inveja ou raiva e conseguir recalcar esses sentimentos. Nesse caso, eles "desaparecem" da consciência, o que não significa que deixem de existir: tornam-se inconscientes e, basta que os mecanismos de defesa falhem para que voltem a influenciar as condutas. Logo, pensamos que colocar limites restritivos sobre os sentimentos é tarefa impossível.

Todavia, isso não quer dizer que nada se possa fazer para trabalhar a raiva, o ódio, a inveja, e outros sentimentos cujas traduções em ações costumam contradizer os deveres morais, e trabalhar também aqueles que os possibilitam ou facilitam, como a compaixão, a simpatia, o amor. O trabalho é possível, mas, é claro, não no sentido do limite restritivo, mas sim do limite no seu sentido de superação. E essa afirmação nos traz de volta ao tema moral das virtudes.

A análise moral e psicológica das virtudes é, evidentemente, complexa. Do ponto de vista filosófico, é complexa por que, desde a Antigüidade, discute-se a inclusão das virtudes na moral, e a definição e valor de cada uma. E, do ponto de vista psicológico, a complexidade advém do fato de praticamente não existirem estudos sobre elas, fato este explicado pela opção da maioria das éticas modernas (às quais tem se filiado a Psicologia moral do século 20) por sistemas axiomáticos que contemplam princípios e regras, o que implica em eleger a virtude "justiça" como única digna de atenção. Felizmente, filósofos contemporâneos têm resgatado a discussão sobre as virtudes (como Tugendhat, MacIntyre e Comte-Sponville), mas suas propostas ainda têm pouca penetração na psicologia moral. Remetemos o leitor a outro texto para um equacionamento mais detalhado da relação entre, por um lado, as virtudes e a moral, e, por outro, entre elas e a Psicologia moral (LA TAILle, 2000). Por ora, vamos nos limitar à apresentação de três pontos que, cremos, esclarecem a relação entre moral e limites a serem superados.

O primeiro é derivado da própria definição de virtude, a saber, característica boa, ou, até, admirável do caráter. Logo, virtude remete à idéia de excelência, vale dizer, à de crescimento, de auto-aperfeiçoamento referida por Kant. Nos termos deste artigo, virtude remete a superação de limites, no caso, daqueles relacionados à disposições de caráter.

O segundo ponto a ser abordado remete à função das virtudes na moral. Como vimos, para vários filósofos (Aristóteles, por exemplo), a moral define-se como busca da felicidade, como arte de viver, como esforço para 
se chegar à sabedoria (que alia busca integrada da verdade e da felicidade). Ora, nesta perspectiva, não somente as virtudes constituem condição necessária ao alcance da felicidade como seu exercício é, em si, fonte de felicidade. Vale dizer que a superação de si, a superação dos próprios limites, é indissociável da moral.

Os dois pontos que acabamos de colocar pertencem à dimensão moral, portanto filosófica. Mas percebemos facilmente o quanto trazem uma implicação importante para a dimensão psicológica: o desenvolvimento moral (em direção à sabedoria) depende de um trabalho sobre si mesmo, trabalho este que longe de ser apenas uma "contenção" da razão e dos afetos, é essencialmente uma expansão ou uma superação destes.

Já falamos da expansão da razão lembrando que há um desenvolvimento do juízo moral. Falemos um pouco mais da parte afetiva. Verificamos que, a cada virtude, corresponde um ou vários sentimentos, e que tal correspondência significa superação. Por exemplo, coragem é superação do medo (não sua ausência, pois o medo tem função psicológica importante para a sobrevivência). Outro exemplo: generosidade é superação do egoísmo (e também não sua ausência, por que "pensar em si" também é necessário à sobrevivência e à própria felicidade). Outro exemplo ainda: a humildade é superação da vaidade ou do orgulho (e não sua ausência por que é inevitável que haja investimento afetivo sobre si próprio). Nos três exemplos que acabamos de dar, a superação de limites está relacionada ao erguer-se acima de si para não ser dominado por afetos que, se não trabalhados, levariam a ações negativas. Mas podemos também pensar a superação de limites como expansão e aprimoramento de sentimentos positivos: a generosidade pode ser decorrência da expansão da compaixão, da simpatia e do amor. Mesma coisa pode ser dita da gratidão e da fidelidade.

Podemos agora voltar a nosso dilema pedagógico: é preferível colocar o limite restritivo sobre a ação (não pode bater) e trabalhar o afeto que motivou a ação violenta por meio da superação. E mesmo para aqueles que pensam que a moral apenas diz respeito a deveres, à limitação da liberdade, respondemos duas coisas. A primeira, é muito difícil uma pessoa que incessantemente sente ódio, raiva e inveja, sempre conseguir conter as ações que extravasam esses afetos. Logo, os limites no sentido restritivo dependem daqueles que são superados. A segunda: o que seria da moral se não houvesse o cultivo das virtudes? Mesmo que fiquemos com a "justiça" como única virtude genuinamente moral (e ela implica essencialmente restrição de liberdade derivada do respeito pelos direitos alheios), o que seria dela sem coragem para defendêla, generosidade para dela lembrar em diferentes contextos, humildade para reconhecer que é um ideal perante o qual todos nós somos imperfeitos? As 
virtudes - a superação dos limites - podem tanto permitir que os deveres os limites restritivos - sejam de fato obedecidos, como fazer com que não sejam interpretados de forma dogmática. Pensar apenas nos limites restritivos na educação moral é condenar-se a uma "moral triste", como o diz Comte-Sponville (1995) e, na prática, inoperante.

\section{REFERÊNCIAS}

ARISTÓTELES. Ethique de Nicomade. Paris: Flamarion, 1965.

COMTE-SPONVILLE, A. Petit traité des grandes vertus. Paris: PUF, 1995.

DURKHEIM, E. L'Education morale. Paris: PUF, 1902/1974.

FREUD, S. Malaise dans la civilisation. Paris: PUF, 1929/1971.

FREUD, S. Le moi et le ça. Paris: PUF, 1922/1991.

KANT, E. Métaphysique des moeurs, deuxième partie: doctrine des vertus. Paris: Vrin, 1797/1985.

KOHLBERG, L. Essays on moral development. S. Francisco: Harper \& Row, 1981.

LA TAILLE, Y. Para um estudo psicológico das virtudes. Educação e pesquisa. São Paulo, v. 26, n. 2, p.109-122, 2000.

MACINTYRE, A. After virtue: a study in moral theorie. London: University of Notre Dame Press, 1981.

PASCAL. Pensées. Paris: Le Livre de Poche, 1670/1972.

PIAGET, J. Le Jugement Moral chez l'enfant. Paris: PUF, 1932/1992.

PIAGET. J. De la pédagogie. Paris: Odile Jacob, 1998.

SMITH, A. Théorie des sentimentos moraux. Paris: PUF, 1723/1999.

SPINOZA. L'ethique. Paris: Gallimard, 1677/1954.

TUGENDHAT, E. Conférences sur l'éthique. Paris: PUF, 1998.

Texto recebido em 10 de fev. 2002

Texto aprovado em 22 de abr. 2002 